\title{
12 Lead Placement Chest
}

National Cancer Institute

\section{Source}

National Cancer Institute. 12 Lead Placement Chest. NCI Thesaurus. Code C71112.

An electrocardiogram (ECG) lead placement whereby 12 leadpoints are recorded but the standard lead positions have been modified so that all leads on the chest are part of a single electrode pad. 